\title{
Hepatic and extrahepatic expression of serum amyloid A3 during lactation in dairy cows ${ }^{1}$
}

\author{
B. Saremi, ${ }^{*}$ M. Mielenz, ${ }^{* 2,3}$ M. M. Rahman, ${ }^{*}$ A. Hosseini, ${ }^{*}$ C. Kopp,${ }^{*}$ S. Dänicke, $†$ F. Ceciliani, $\neq$ \\ and $H$. Sauerwein* \\ *Institute of Animal Science, Physiology \& Hygiene Unit, University of Bonn, Katzenburgweg 7 - 9, 53115 Bonn, Germany \\ †Institute of Animal Nutrition, Friedrich-Loeffler-Institute (FLI), Federal Research Institute for Animal Health, Bundesallee 50, \\ 38116 Braunschweig, Germany \\ ‡Department of Veterinary Science and Public Health, Università di Milano, Via Celoria 10, 20133 Milan, Italy
}

\section{ABSTRACT}

Serum amyloid A3 (SAA3) is the predominant SAA isoform secreted by mammary epithelial cells in dairy cows; it is also expressed in bovine adipose tissue (AT). The adipokine SAA3 is linked to obesity and insulin resistance of AT and the respective inflammatory response, at least in mice. Dietary treatment with conjugated linoleic acids (CLA) reportedly also affects insulin sensitivity and inflammatory status in monogastrics. Both SAA3 and CLA thus seem to alter similar functions. Based on changes in insulin sensitivity and the inflammatory status throughout lactation, we hypothesized that the mRNA abundance of $S A A 3$ in various tissues might be regulated as well and that CLA could be a modulator of SAA3 mRNA expression. In 2 trials, 21 pluriparous and 25 primiparous Holstein cows were fed $100 \mathrm{~g} / \mathrm{d}$ of a CLA or a control fat supplement from d 1 to 182 or 105 postpartum, respectively. Biopsies from liver and subcutaneous (s.c.) AT from pluriparous cows and samples from 3 different visceral AT and 3 s.c. AT, muscle, mammary gland, and liver tissue from slaughtered primiparous cows were obtained. In an adipocyte cell culture system, cell samples were collected during differentiation of bovine preadipocytes at $\mathrm{d} 0,2,6,8,10,12$, and 13 relative to the onset of differentiation. The $S A A 3 \mathrm{mRNA}$ abundance in tissues and in differentiating bovine preadipocytes was measured by real-time PCR. The presence of the SAA protein was confirmed by Western blotting. Treatment with CLA yielded only few and inconsistent effects on

\footnotetext{
Received December 17, 2012.

Accepted August 7, 2013.

${ }^{1}$ Corrected PDF showing a revised DOI.

${ }^{2}$ Corresponding author: mielenz@fbn-dummerstorf.de

${ }^{3}$ Present address: Manfred Mielenz, Institute of Nutritional Physiology "Oskar Kellner," Leibniz Institute for Farm Animal Biology (FBN), Wilhelm-Stahl-Allee 2, 18196 Dummerstorf, Germany.

${ }^{4}$ Present address: Mammalian NutriPhysioGenomics, Division of Nutritional Sciences, 428 Animal Sciences Laboratory, Department of Animal Sciences, University of Illinois, 1207 W. Gregory Drive, Urbana 61801.
}

SAA3 mRNA abundance. In both trials, SAA3 mRNA peaked at $\mathrm{d} 1$ postpartum in all tissues except in mesenteric AT, in which the change was not significant. The highest $S A A 3$ mRNA expression was observed in the mammary gland, followed by omental AT. The SAA protein was present in the visceral and s.c. AT depots investigated. Adipocytes as one source of $S A A 3$ were confirmed by the $S A A 3$ mRNA profile in differentiating adipocytes. The longitudinal changes observed point to $S A A 3$ being involved in the inflammatory situation around parturition.

Key words: serum amyloid A3 (SAA3), conjugated linoleic acid, adipose tissue, dairy cow

\section{INTRODUCTION}

Serum amyloid A (SAA) is a major acute-phase protein in cattle and has been proven as a diagnostic marker (Eckersall and Bell, 2010). The biological functions identified up to now include cholesterol transport as well as modulation of immune reaction (Ceciliani et al., 2012). Acute-phase SAA comprises 2 closely related isoforms (SAA1 and SAA2), which are expressed mainly in the liver in response to proinflammatory stimuli; further members of the SAA family are SAA3 and SAA4, whereby SAA3 is mainly extrahepatically expressed under proinflammatory conditions in several mammalian species (Uhlar and Whitehead, 1999). The isoform SAA4 is constitutively expressed and responds only moderately to inflammatory stimuli (de Beer et al., 1996). Due to its synthesis and secretion from adipose tissue (AT), SAA3 was also classified as an adipokine (Lin et al., 2001) and the circulating concentrations of SAA correlate with obesity and insulin resistance in humans (Ebeling et al., 1999; Yang et al., 2006). However, using tandem mass spectrometry, no SAA3 protein was observed in circulating high-density lipoproteins, albeit secretion of SAA3 from cultured adipocytes was confirmed (Chiba et al., 2009). Therefore, in consequence of the fact that SAA3 is not transported by highdensity lipoproteins, adipose tissue-derived SAA3 is not involved in increasing SAA blood concentrations in 
association with obesity and insulin resistance (Chiba et al., 2009).

In cattle, SAA proteins were characterized in 1988 (Husebekk et al., 1988) and SAA3 is the predominant SAA isoform secreted by mammary gland epithelial cells in response to gram-negative (Larson et al., 2005) or gram-positive bacteria (Weber et al., 2006). Based on its mammary localization, it is also termed mammary SAA3 (McDonald et al., 2001) and is assumed to protect the mammary tissue during remodeling and infection (Molenaar et al., 2009). The SAA3 mRNA has been detected in bovine AT, but its expression is apparently not upregulated by LPS (Mukesh et al., 2010; Berg et al., 2011). Remarkably, SAA is regulated by nutritional changes, as caloric restrictions are associated with downregulation of SAA, both at the mRNA and the protein level (Poitou et al., 2005).

Conjugated linoleic acids (CLA) are compounds that are discussed to be related to insulin sensitivity and inflammatory status of the body. The cis-9,trans-11 CLA isomer improves insulin sensitivity and reduces proinflammatory cytokines (Reynolds and Roche, 2010); the trans-10, cis-12-CLA isomer adversely promotes inflammation in human adipocytes (Martinez et al., 2010) and induces lipolysis and insulin resistance (Rubin et al., 2012). Dietary CLA supplements alter lipid metabolism: in dairy cows, the trans-10, cis-12 CLA has been reported to specifically target the mammary gland, reducing milk fat synthesis (Baumgard et al., 2001), whereas cis-9,trans-11 CLA had less effect (Perfield et al., 2007). In contrast to other monogastric species, body fat mass has been shown to be unaffected by CLA treatment in dairy cows (von Soosten et al., 2011); however, we recently observed that fat cell size in primiparous cows receiving a 1:1 mixture of cis9,trans-11 CLA and trans-10,cis-12 CLA was decreased when compared against a control group (Akter et al., 2011).

The energy requirements for milk yield and maintenance exceed energy intake by voluntary feed intake during the first weeks of lactation, in particular in high-yielding dairy cows. Prioritizing milk secretion, the insulin sensitivity of peripheral tissues other than the mammary gland is decreased and body reserves mainly from AT are mobilized and imply an increased risk for metabolic diseases, mainly ketosis and fatty liver. As discussed by (Bauman et al., 2011), reducing the energy output via milk by decreasing the milk fat content through feed supplements containing CLA may attenuate the negative energy balance during this period. However, based on increasing milk yield, Hutchinson et al. (2012) observed no differences in milk energy output. In contrast, Castañeda-Gutiérrez et al. (2005) reported a dose-dependent reduction in milk en- ergy output, whereby energy balance was not altered. Also, Bernal-Santos et al., (2003) reported no changes in total energy output during early lactation, which is in line with the observations of Moore et al. (2004), who detected no effect on BCS and other production parameters.

In view of the connection between SAA3 expression and lipid metabolism, we aimed to characterize the changes of $S A A 3$ mRNA in AT and other metabolically important tissues throughout lactation. In particular, we aimed to compare $S A A 3 \mathrm{mRNA}$ abundance in different visceral (v.c.) and s.c. fat depots and to qualitatively characterize the SAA protein expression in these depots. Moreover, to confirm adipocytes as an SAA3producing cell type of AT, we quantified $S A A 3$ mRNA in differentiating bovine preadipocytes. In addition, we tested for potential CLA effects on SAA3 mRNA.

\section{MATERIALS AND METHODS}

The experiments and treatments of the animals were approved by the competent authority, the Lower Saxony state office for consumer protection and food safety (LAVES, file no. 33.11.42502-04-071/07; Oldenburg, Germany). The regulations of the German Animal Welfare Act (TierSchG) in its respective current edition were met. All animals were housed at the experimental station of the Friedrich Loeffler Institute, Federal Research Institute for Animal Health, Braunschweig, Germany.

\section{Animal Experiments}

Trial 1. German Holstein pluriparous cows $(\mathrm{n}=21)$ were fed ad libitum in the entire experimental period according to the recommendations of the German Society of Nutrition Physiology (GfE, 2001). Details and outcomes in terms of diet, performance, metabolite concentrations and milk fat FA profile from this experiment are described by Pappritz et al. (2011). From d 1 postpartum (p.p.), the animals were allocated to 2 groups: a CLA and a control group (10 and 11 cows, respectively), each receiving $100 \mathrm{~g} / \mathrm{d}$ of fat supplement during the supplementation period from d 1 to 182 p.p. The animals of the CLA group received encapsulated CLA (Lutrell Pure; BASF SE, Ludwigshafen, Germany). The control group received an analogous isoenergetic FA mixture (Silafat; BASF SE) in which CLA were substituted by stearic acid. The animals of the CLA group consumed $7.6 \mathrm{~g} / \mathrm{d}$ each of trans-10, cis-12 CLA and cis-9,trans-11 CLA (calculated, based on the analyzed proportions in the concentrate) and expectedly responded with reduced milk fat content to the CLA treatment, whereas energy balance was not 
altered during most of the supplementation period (Pappritz et al., 2011). The compositions of the control and the CLA-containing FA supplements can be found in Supplemental Table S1 (available online at http:// dx.doi.org/10.3168/jds.2012-6495). Liver and s.c. AT from the tailhead region were biopsied as described earlier (Saremi et al., 2012a) on d -21, 1, 21, 70, 105, 182, 196, 224, and 252 from control cows and d $-21,21,105$, 196, and 252 from CLA cows relative to parturition.

Trial 2. German Holstein primiparous cows $(\mathrm{n}=25$; average age at parturition: $23 \mathrm{mo}$ ) were fed ad libitum according to the recommendations of the German Society of Nutrition Physiology (GfE, 2001). Five animals were slaughtered $1 \mathrm{~d}$ p.p. and the remaining cows $(\mathrm{n}=$ 20) were allocated randomly to either control or CLA fat supplement similar to trial 1 starting from d 1 p.p. until slaughter. Additional information about the diets and the main outcomes in terms of body composition is available elsewhere (von Soosten et al., 2011). Five animals per group were slaughtered p.p. at d 42 and 105. Samples from 3 v.c. AT (omental, mesenteric, and retroperitoneal), 3 s.c. AT (tailhead, withers, and sternum), liver, semitendinosus muscle, pancreas, and mammary gland were collected immediately after slaughter. In general, efficacy of the CLA treatment in terms of milk fat reduction was demonstrated but the calculated energy balance was not significantly altered by CLA treatment. Neither NEFA serum concentrations nor BCS indicated an effect of the CLA treatment on lipolysis and body fat. However, back fat thickness was decreased in the CLA group (d 42 to 105 interval; von Soosten et al., 2011) and adipocyte sizes were decreased in 2 and 4 out of 6 different fat depots on d 42 and 105, respectively (Akter et al., 2011).

\section{Culture and Differentiation of Bovine Preadipocytes}

In a separate experiment, s.c. AT around sternum was obtained from 3 additional Holstein dairy cows at slaughter. Tissue treatment, cell separation, culture, and differentiation conditions are described in detail by Hosseini et al. (2012). Isolated stromal vascular cells of the 3 cows were pooled and differentiated. Cell samples of preadipocytes were taken at d $0,2,6,8,10,12$, and 13 relative to the onset of differentiation. Primary cell samples from the given day of differentiation were assayed in triplicate.

The samples from both trials were snap frozen in liquid nitrogen. The samples from the cell culture experiment were preserved in TRIzol (Invitrogen $\mathrm{GmbH}$, Karlsruhe, Germany). All samples were stored at $-80^{\circ} \mathrm{C}$ until further use.

\section{RNA Extraction, cDNA Synthesis, and Relative Quantification by Real-Time PCR}

Handling of samples to quantify mRNA using realtime PCR was described in detail earlier (Saremi et al., 2012a,b). The SAA3 primers (forward: GGGCATCATTTTCTGCTTCCT and reverse: TTGGTAAGCTCTCCACATGTCTTTAG) were as described by Mukesh et al. (2010) and the primer amount used was 8 pmol per reaction. The PCR conditions were 10 min at $95^{\circ} \mathrm{C}$ for initial denaturation, $30 \mathrm{~s}$ at $95^{\circ} \mathrm{C}$ for denaturation, $60 \mathrm{~s}$ at $60^{\circ} \mathrm{C}$ for annealing, and $30 \mathrm{~s}$ at $72^{\circ} \mathrm{C}$ for extension. A PCR amplicon standard curve was used to estimate PCR efficiency per each real-time PCR run. Two microliters of cDNA (diluted 1 to 4 ) as template and $5 \mu \mathrm{L}$ of SYBR Green JumpStart Taq ReadyMix (Sigma-Aldrich Chemie GmbH, Steinheim, Germany) in a total volume of $10 \mu \mathrm{L}$ were run in an Mx3000P real-time PCR instrument (Agilent Technologies Inc., Santa Clara, CA). For normalization of the efficiencycorrected data, reference genes from the following panel were selected and used, depending on the trial and the tissues in the comparison (Saremi et al., 2012a,b). Vandesompele et al. (2002) suggested optimizing a panel of reference genes for each experiment individually. We followed this concept and the MIQUE guidelines (Bustin et al., 2009) for both data sets, causing a different panel of reference genes in the 2 independent trials. For trial 1, GAPDH, lipoprotein receptor-related protein 10 (LRP10), RNA polymerase II (POLR2A), and eukaryotic translation initiation factor 3 (EIF3K) were selected for s.c. fat, and LRP10, POLR2A, and EIF3K were selected for the liver. For trial 2, EIF3K, LRP10, POLR2A, emerin (EMD), Marvel domain-containing 1 (MARVELD1), and hippocalcin-like 1 (HPCAL1) were used. The data used for statistics was generated by geNorm $^{\text {PLUS }}$ as a part of qbase ${ }^{\text {PLUS }}$ version 2.0 (Biogazelle NV, Ghent, Belgium).

\section{Western Blot Analysis}

Omental, mesenteric, retroperitoneal, and tailhead AT and liver samples (d 105 p.p.) from a control cow in trial 2 were exemplarily used for characterizing the SAA protein in these tissues. Tissues were homogenized in HEPES buffer $(10 \mathrm{~m} M$, $\mathrm{pH}$ 7.4) using a Precellys system (Peqlab Biotechnologie GmbH, Erlangen, Germany). The total protein content was quantified by the bicinchoninic acid method (BCA; Sigma-Aldrich) and equal amounts of protein $(15 \mu \mathrm{g})$ were loaded in $16 \%$ Tris-tricine-SDS gels. After electrophoresis, the gels were blotted onto polyvinyl difluoride membranes (GE Healthcare Bio-Science GmbH, Munich, Germany). 
The membranes were immunolabeled for the presence of SAA using a rabbit anti-bovine SAA antibody (10.1 $\mathrm{mg} / \mathrm{mL}$ ) diluted 1:4,000 and the antibody-antigen complexes were tagged with horseradish peroxidase coupled to a secondary goat anti-rabbit IgG antibody (SouthernBiotech, Birmingham, AL). Detection was carried out by enhanced chemiluminescence (GE Healthcare UK Ltd., Buckinghamshire, UK). To confirm that an equal amount of protein was loaded on each lane, membranes were stripped and immunolabeled with a mouse anti-human $\beta$-actin antibody $(0.5 \mathrm{mg} / \mathrm{mL})$, 1:2,000 dilution (BioVision, Mountain view, CA), and horseradish peroxidase-labeled goat anti-mouse $\operatorname{IgG}$ (SouthernBiotech).

\section{Statistical Analyses}

All statistical analyses were performed using SPSS (version 20; SPSS Inc., Chicago, IL). For trial 1, the mixed-model procedure was used. Treatments (control and CLA) were considered as fixed factors, and sampling dates (time) as a repeated effect; the respective interaction was also included in the model. The covariance structure component symmetry and Bonferroni correction were used. For trial 2, all data were tested for homogeneity of variance $(P<0.1)$. Homogeneity of variance was significantly different. Thus, nonparametric tests (Kruskal-Wallis or Mann-Whitney) were used. A $P$-value $<0.05$ was considered significant.

\section{RESULTS}

\section{Trial 1}

Liver $S A A 3$ mRNA abundance was maximal at the day of parturition (8-fold higher than the mean of the other days antepartum and p.p. but remained fairly stable throughout all the other days; Figure 1). In s.c. AT from the tailhead, the day of parturition was significantly different compared with 196 and 252 d p.p. (7.7fold higher $S A A 3$ mRNA abundance). Supplementation with CLA compared with the control group yielded no significant effects on $S A A 3$ mRNA abundance in liver and s.c. AT. To be able to compare $S A A 3 \mathrm{mRNA}$ in s.c. $\mathrm{AT}$ and liver tissue, a similar set of reference genes was needed. Therefore, the geometric mean of POLR2A and EIF3K was used. Taking into account all data across times and treatment, the SAA 3 mRNA abundance was slightly higher (1.25 fold) in s.c. tailhead AT than in liver.

\section{Trial 2}

Decreasing mRNA abundance of $S A A 3$ from d 1 to 42 and 105 was observed in all fat tissues except mes- enteric AT, in which $S A A 3$ was constantly expressed (Figure 2). The decrease in SAA3 mRNA abundance in liver and muscle tissues was significant between $\mathrm{d} 1$ and 42 and in the mammary gland was similar to the AT depots (Figure 3 ). In pancreatic tissue, the presence of $S A A 3$ mRNA was confirmed (data not shown), but due to the low quality of the RNA extracted no statistics were done for this tissue. The decline in $S A A 3 \mathrm{mRNA}$ abundance from d 1 to 42 and 105 was different between tissues: s.c. AT from the tailhead, retroperitoneal AT, s.c. AT from the sternum, s.c. AT from the withers, and omental and mesenteric AT had $44.1>31.5>21.8$ $>7.67>5.9>1.8$-fold higher SAA3 mRNA abundance at d 1 compared with the mean of d 42 and 105, respectively. In case of the mammary gland, muscle, and liver tissues, the reduction was $34.4>7.5>1.0$ fold, respectively. Supplementation with CLA caused a reduction in the abundance of $S A A 3$ mRNA compared with the control group [i.e., in s.c. withers AT at d 42 p.p. (5.8-fold decrease), in s.c. AT from the sternum at d 105 p.p. (3.33-fold decrease), and in muscle tissue at d 105 p.p. (7.98-fold decrease)].

We mathematically pooled the data from different days $(1,42$, and 105 p.p.) and treatments per tissue to be able to compare the $S A A 3$ mRNA abundance between different tissues (i.e., mammary gland, liver, and the 6 different AT) using a panel of reference genes showing the highest expression stability evaluated by geNorm $^{\text {PLUS }}$ (Figure 4). The SAA3 mRNA had its highest expression in the mammary gland (i.e., 20-fold higher expression compared with the mean of AT and 33 -fold higher than liver tissue). The second-highest mRNA expression was in omental AT that was 2- to 26fold greater than in the other 5 fat depots (Figure 4). Depending on the fat depot, the SAA3 mRNA abundance in AT was either greater or smaller than in the liver: the values in 2 s.c. depots (from the tailhead and sternum) and in omental fat exceeded the ones from the liver by a factor of $2.4,1.4$, and 5.3 , respectively. The values in the remaining depots amounted to $20 \%$ (s.c. from the withers and retroperitoneal AT) and $40 \%$ (mesenterial AT) of the ones in liver.

\section{Culture and Differentiation of Bovine Preadipocytes}

The SAA3 mRNA expression in an adipose cell culture system was low in nondifferentiated adipocytes (d 0 ) compared with other stages of differentiation. At d 2 of differentiation, $S A A 3 \mathrm{mRNA}$ increased by a factor of 91 compared with d 0 . Thereafter (at d 6, 8, 10, 12, and 13), SAA3 mRNA abundance decreased to values that were still 10-, 3.9-, 4-, 1.6-, and 1.3-fold higher than on d 0 of differentiation, respectively (Figure 5). 

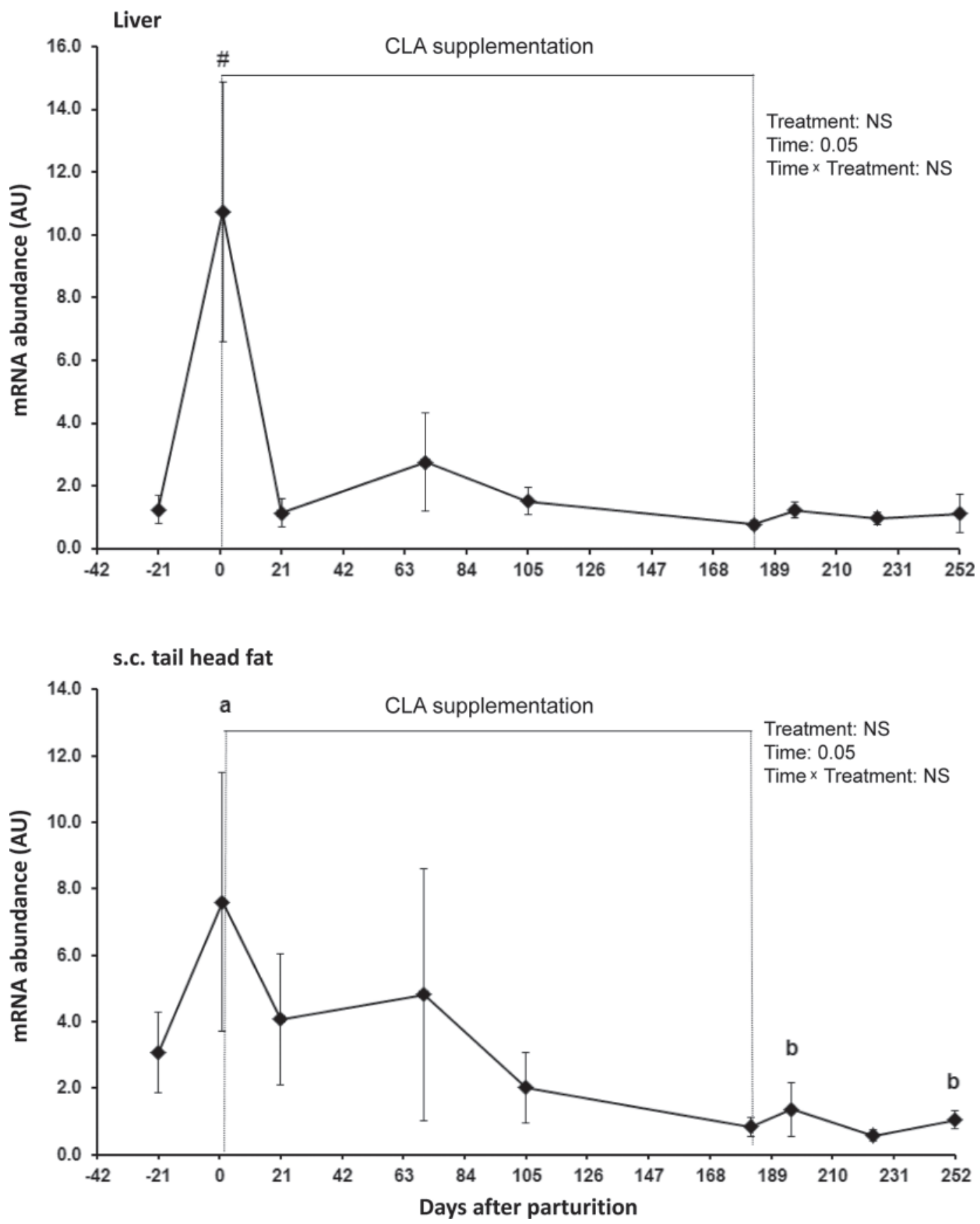

Figure 1. Serum amyloid A3 (SAA3) mRNA abundance (means \pm SEM) in liver and in s.c. tailhead fat of pluriparous cows. Based on the lack of significant treatment effects, data were pooled from cows receiving conjugated linoleic acids (CLA; Lutrell Pure; BASF SE, Ludwigshafen, Germany; $\mathrm{n}=11$ ) at $100 \mathrm{~g} / \mathrm{d}$ and from cows receiving a control fat supplement (Silafat; BASF SE; $\mathrm{n}=10$ ) from d 1 to 182 postpartum in trial 1. Samples from d 1, 70, 182, and 224 were limited to the control cows. In liver, \# represents a significant difference compared with all the other sampling dates $(P<0.05)$. Different letters $(\mathrm{a}$ and $\mathrm{b})$ indicate significant differences between days relative to parturition $(P<0.05)$. Data are normalized based on the geometric mean of the 3 most-stable reference genes: lipoprotein receptor-related protein 10 ( $L R P 10)$, RNA polymerase II (POLR2A), and eukaryotic translation initiation factor 3 (EIF3K) in the liver and LRP10, GAPDH, and POLR2A in s.c. adipose tissue. AU $=$ arbitrary units.

\section{Detection of the SAA Protein in AT}

Expression of SAA protein was confirmed by Western blot analysis in different bovine fat depots (Figure
6). Immunoreactive bands were mainly detected as a 14-kDa monomer. In addition, bands of about 26 to 28 $\mathrm{kDa}$ and 52 to $56 \mathrm{kDa}$ likely to be the SAA dimer and tetramer were observed. Other faint bands of higher 


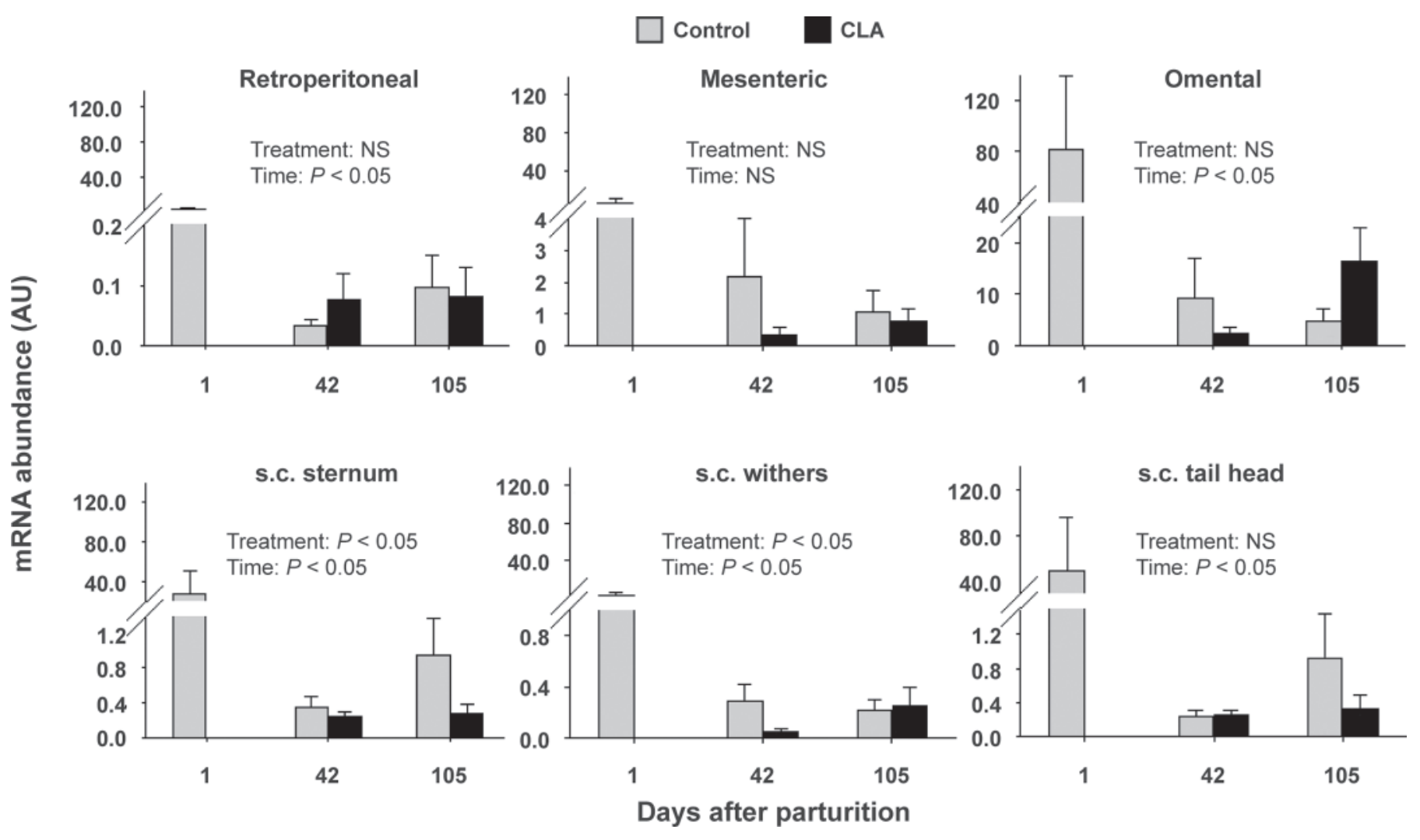

Figure 2. Serum amyloid A3 (SAA3) mRNA abundance (means \pm SEM) in 3 visceral (upper panels) and 3 s.c. fat depots (lower panels) in primiparous cows supplemented with $100 \mathrm{~g} / \mathrm{d}$ of conjugated linoleic acids (CLA; Lutrell Pure; BASF SE, Ludwigshafen, Germany) or a control fat supplement (Silafat; BASF SE) from d 1 to 105 postpartum. Within the control group, SAA3 mRNA abundance was higher $(P<0.05)$ on d 1 than on d 42 and 105 in retroperitoneal and omental fat. In s.c. fat from the sternum, withers, and tailhead, the difference was limited to d 1 versus 42 and in omental fat, an additional decrease was observed from d 42 to 105 . The effects of CLA treatment were limited to s.c. fat in which reduced SAA3 mRNA abundance was observed at d 42 and 105 in s.c. fat from the withers and sternum, respectively. Data are normalized based on the geometric mean of the most-stable reference genes: eukaryotic translation initiation factor 3 (EIF3K), lipoprotein receptorrelated protein 10 (LRP10), RNA polymerase II (POLR2A), emerin (EMD), Marvel domain-containing 1 (MARVELD1), and hippocalcin-like 1 (HPCAL1) for each s.c. fat and mesenteric fat depot and EIF3K, LRP10, POLR2A, EMD, and MARVELD1 for omental and retroperitoneal fat depots. $\mathrm{AU}=$ arbitrary units.

molecular weight probably resulted from the association of SAA with other proteins (e.g., albumin).

\section{DISCUSSION}

\section{Expression of SAA3 MRNA in AT, Mammary Gland, and Liver}

When ranking the different tissues investigated herein according to their SAA3 mRNA abundance, the mammary gland had the highest values and was followed by some AT depots exceeding the abundance in the liver, whereas other AT depots ranked below the liver. This indicates that SAA3 might be important for AT functions. However, protein expression and secretion of SAA3 from AT needs to be clarified in the future. No data are available showing contribution of mammary $S A A 3$ to blood; it is mainly secreted to colostrum and milk (Molenaar et al., 2009). Secretion of SAA3 into the medium of a murine adipocyte culture was already shown, but a significant contribution to circulating SAA from AT was considered improbable (Chiba et al., 2009). In murine AT, SAA3 was identified as the major SAA isoform (Sommer et al., 2008). However, no selective antibody for bovine SAA3 is available; using the anti-bovine SAA antibody, a SAA monomer of comparable size, as shown by Dilda et al. (2012), was detectable in different AT at the protein level. Different bands in addition to the monomer are probably related to multimerization and association with other proteins. Indeed, SAA may form polymers during storage and freezing/thawing of samples (Molenaar et al., 2009). Other factors that might affect structure and stability of SAA are different metal ions and their concentration at least in in vitro conditions (Wang and Colón, 2007).

The abundance of $S A A 3$ mRNA varied considerably between the different bovine AT investigated herein, but explanations for the underlying reasons and func- 


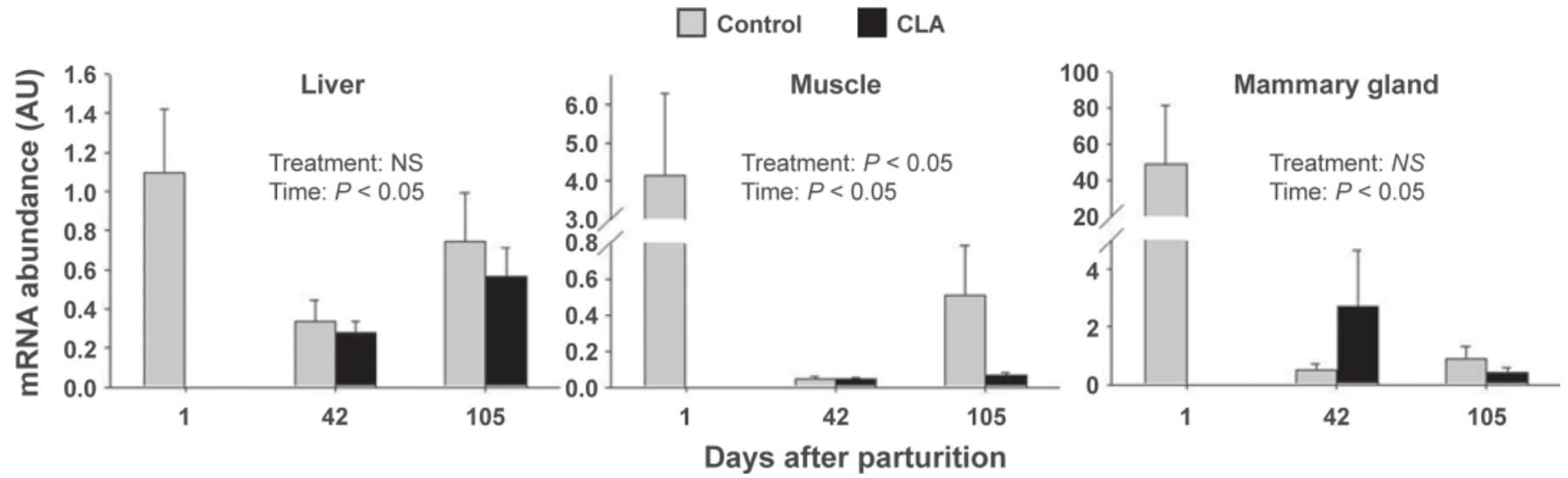

Figure 3. Serum amyloid A3 (SAA3) mRNA abundance (means \pm SEM) in the liver, semitendinosus muscle, and mammary gland of primiparous cows receiving conjugated linoleic acids (CLA; Lutrell Pure; BASF SE, Ludwigshafen, Germany) at $100 \mathrm{~g} / \mathrm{d}$ or a control fat supplement (Silafat; BASF SE) from d 1 to 105 postpartum. Significant differences between sampling dates within tissue of the control group were between $\mathrm{d} 1$ and 42 in the liver, muscle, and mammary gland $(P<0.05)$. At d 105, SAA3 mRNA abundance remained low in the mammary gland, but increased to the values of d 1 in liver and muscle tissue. Effects of CLA were limited to d 105 postpartum in muscle tissue. Data are normalized based on the geometric mean of the most-stable reference genes: hippocalcin-like 1 (HPCAL1), lipoprotein receptor-related protein 10 (LRP10), RNA polymerase II (POLR2A), eukaryotic translation initiation factor 3 (EIF3K), and GAPDH for the liver; LRP10, emerin $(E M D), P O L R 2 A$, and EIF3K for muscle; and Marvel domain-containing 1 (MARVELD1), EMD, LRP10, EIF3K, POLR2A, and HPCAL1 for mammary gland tissue. AU = arbitrary units

tions are lacking. No general difference was observed between s.c. and v.c. fat depots and neither the portion of the fat depots nor their readiness for mobilization as concluded from BW composition at the different sam-

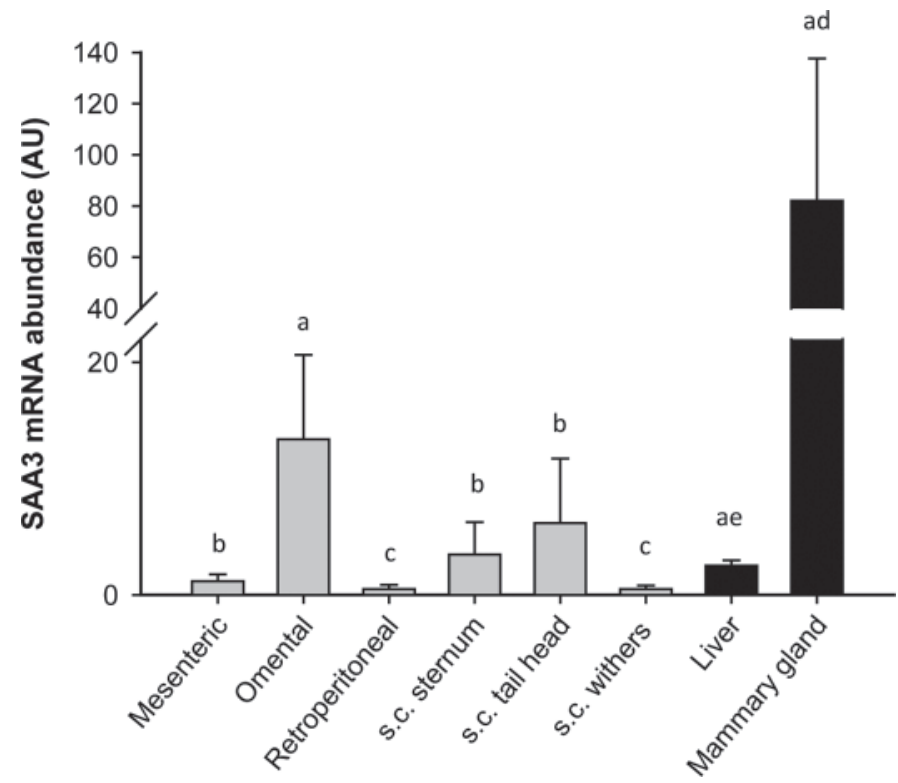

Figure 4. Serum amyloid A3 (SAA3) mRNA abundance (means \pm SEM) in different fat and non-fat tissues of primiparous cows across all sampling dates and treatments. Different letters (a-e) specify the differences between the individual fat depots $(P<0.05)$. Data are normalized based on the geometric mean of the 4 most-stable reference genes: eukaryotic translation initiation factor 3 (EIF3K), lipoprotein receptor-related protein 10 (LRP10), RNA polymerase II (POLR2A), and hippocalcin-like 1 (HPCAL1). $\mathrm{AU}=$ arbitrary units. pling days (von Soosten et al., 2011) seem to be related to $S A A 3 \mathrm{mRNA}$ abundance.

\section{Expression of SAA3 mRNA During Differentiation of Primary Bovine Preadipocytes}

In both undifferentiated and differentiating preadipocytes from s.c. AT of dairy cows, $S A A 3$ mRNA was expressed at low abundance, whereas a peak value

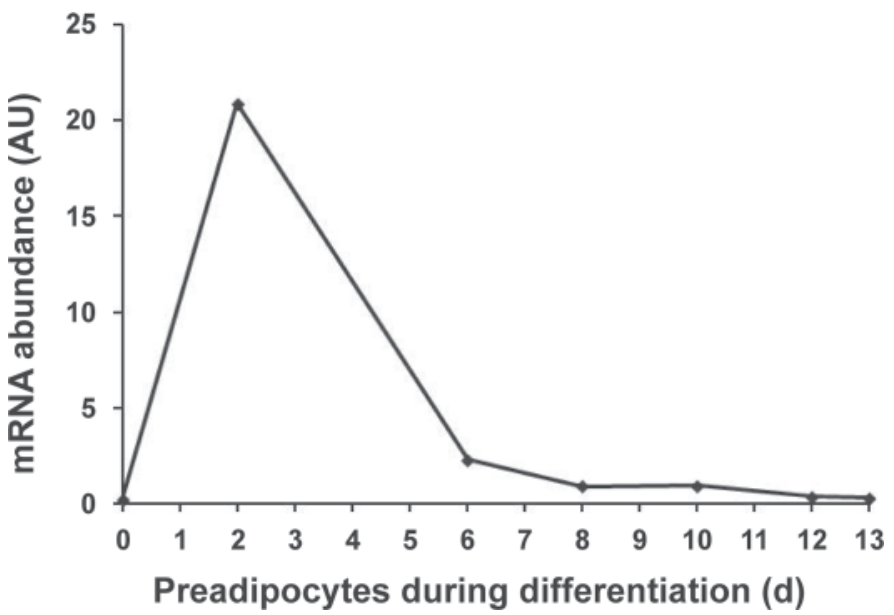

Figure 5. Timely changes of serum amyloid A3 (SAA3) mRNA abundance in bovine preadipocytes differentiating for $13 \mathrm{~d}$. Primary cells were obtained from 3 individuals and were pooled; samples from the given days of differentiation were assayed in triplicate. The mRNA quantities were normalized to the geometric mean of 2 reference genes: $G A D P H$ and lipoprotein receptor-related protein 10 (LRP10). $\mathrm{AU}=$ arbitrary units. 


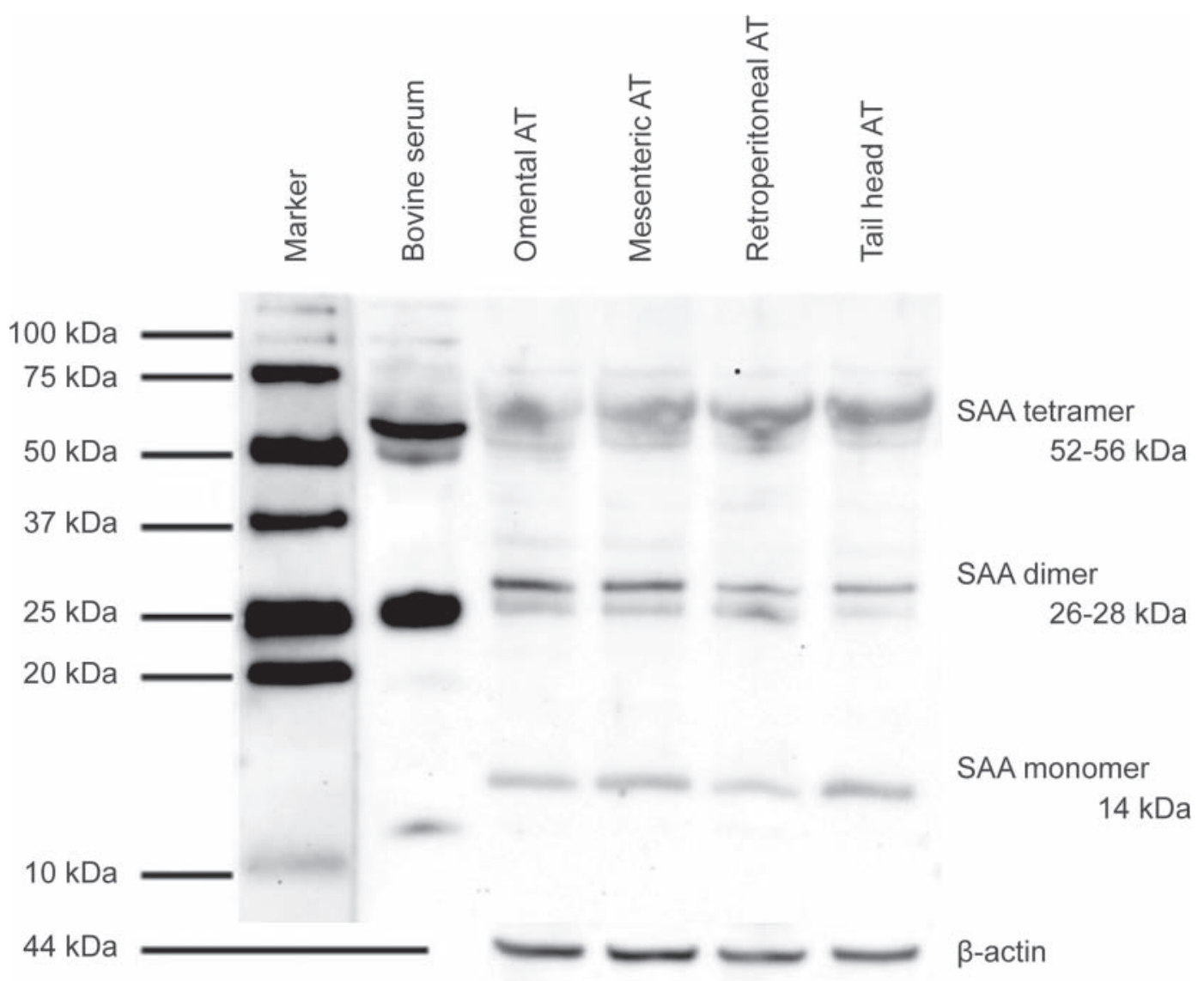

Figure 6. Tris-tricine-SDS gel and Western blot analysis of adipose tissue homogenates from different fat depots. Equal amounts of total protein $(15 \mu \mathrm{g})$ of each tissue homogenate were loaded. Serum amyloid A3 (SAA) was detected using a rabbit anti-bovine SAA antibody. Bovine serum was used as a positive control. To confirm that an equal amount of protein was loaded on each lane, membranes were stripped and immunolabeled with a mouse anti $\beta$-actin antibody. $\mathrm{AT}=$ adipose tissue.

was observed at the onset of differentiation at $\mathrm{d} 2$. We speculate that high expression of $S A A 3$ in $\mathrm{AT}$, but not in differentiated preadipocytes, might be related to the maturity of the preadipocytes and the degree of fat accumulation. However, our cell culture data support that $S A A 3$ can indeed be classified as an adipokine originating from adipocytes.

Dexamethasone, one of the components of the differentiation medium, is known to stimulate $S A A 3 \mathrm{mRNA}$ (Fasshauer et al., 2004). The increase in SAA3 mRNA abundance in differentiating bovine preadipocytes at d 2 supports that $S A A 3$ is positively regulated by glucocorticoids. Thus, it might be similarly linked to insulin sensitivity in bovine AT, as demonstrated in murine adipocytes by Fasshauer et al. (2004).

To date, the biological significance of SAA expression in AT is largely unknown and remains speculative: SAA is an apolipoprotein and is thus involved in binding, transport, and targeting of NEFA mobilized during the peripartum-related lipolysis. Besides, SAA may exert direct metabolic effects on human adipocytes by decreasing lipogenesis through an extracellular signalregulated kinase-dependent pathway. In particular, SAA downregulated peroxisome proliferator activated receptor gamma, CCAAT/enhancer binding protein $\alpha$, and sterol regulatory element binding protein-1c, which in turn, are related to adipocyte differentiation and lipid synthesis (Faty et al., 2012).

\section{Association of SAA3 mRNA With the Inflammatory Reaction in Dairy Cows}

In both trials, the maximum expression of AT SAA3 mRNA was observed in all analyzed tissues at the day of parturition. For the liver, we confirmed the recent observation of highest $S A A 3$ mRNA abundance around parturition in cows (Graugnard et al., 2013). Delivery related stress, tissue lesions, and inflammatory reactions of the genital tract have been suggested as possible explanations for the acute-phase reaction commonly observed at that time (Humblet et al., 2006; Murata, 2007). The involvement of AT in this reaction 
might thus be due to a systemic stimulation of acutephase protein that occurs in all tissues. Although the contribution of SAA3 from AT to the circulating SAA concentrations seems less probable (Chiba et al., 2009), increased $S A A 3$ expression in AT might have a local importance: inflammatory reactions with increased $S A A 3$ in AT have been demonstrated to be related to reduced insulin sensitivity in obese mice (Lin et al., 2001; Reigstad et al., 2009). As mentioned previously, reduced peripheral insulin sensitivity is a common feature in early lactation of dairy cows and might be at least partly attributable to the locally elevated concentrations of SAA3.

Supplementations with CLA are discussed may be related to inflammatory response and insulin sensitivity (Reynolds and Roche, 2010). The sparse effects of CLA treatment on $S A A 3$ mRNA abundance observed herein in some fat depots and in muscle were inconsistent with regard to time, tissue, and direction of change. Nevertheless, the differences established herein indicate that local effects of CLA might exist in these tissues. Both $S A A 3$ mRNA and protein are induced during adipocyte hypertrophy and development of obesity in mice (Han et al., 2007; Scheja et al., 2008; Chiba et al., 2009). In view of the effects of CLA reported in rodents and humans (i.e., reducing body fat and fat cell size), a CLA-induced downregulation of $S A A 3$ in AT was anticipated. However, from all fat depots investigated herein, the s.c. fat had the lowest share of these depots and the CLA treatment largely yielded no effects on fat depot masses (von Soosten et al., 2011). We observed reduced fat cell sizes in both s.c. and v.c. depots from the CLA-treated primiparous cows investigated herein compared with the controls (Akter et al., 2011). However, this CLA-related decrease in cell size coincided with decreased SAA3 mRNA abundance solely in 1 of the fat depots investigated, and thus provides only little support for $S A A 3$ being involved in adipose cellularity. As to whether the CLA effect will remain on the level of the SAA protein remains to be clarified, as the expression of SAA protein in different AT of dairy cows was demonstrated in a qualitative but not a quantitative manner.

Our results using a CLA isomer mixture and the results from a previous study about another acute-phase protein (i.e., haptoglobin; Saremi et al., 2012a) imply that this form of CLA supplementation that is available in the field leaves the major bovine acute-phase proteins largely unaffected. For cattle, the presence of $S A A 3$ mRNA shown herein in pancreatic tissues of dairy cows corroborates earlier studies (Lecchi et al., 2012); however, the functional role of SAA3 in pancreas remains to be investigated.

\section{CONCLUSIONS}

Herein, we defined SAA3 as a new bovine adipokine. Longitudinal characterization of the $S A A 3$ mRNA in $\mathrm{AT}$ and also in non-fat tissues during late pregnancy and the subsequent lactation yielded a peripartal peak. The sparse effects observed for the CLA treatment on SAA3 mRNA abundance in s.c. AT and in muscle tissue do not consistently support that local antiinflammatory effects of CLA might occur; however, this option can also not be entirely ruled out. To clarify potential effects of CLA in this respect, isomer-specific treatments would be more meaningful.

\section{ACKNOWLEDGMENTS}

This study was funded by the German Research Foundation [Deutsche Forschungsgemeinschaft (DFG), Bonn, Germany], grant SA 432/10-1 in PAK 286/1. The authors thank Inga Hofs, Isabella Israel, and Barbara Heitkönig for their skilled technical assistance and Iris Gockel-Böhner (all from Institute of Animal Science, Physiology and Hygiene Unit, University of Bonn, Bonn, Germany) for her help during sampling of the cows.

\section{REFERENCES}

Akter, S. H., S. Häussler, S. Dänicke, U. Müller, D. von Soosten, J. Rehage, and H. Sauerwein. 2011. Physiological and conjugated linoleic acid-induced changes of adipocyte size in different fat depots of dairy cows during early lactation. J. Dairy Sci. 94:2871-2882.

Bauman, D. E., K. J. Harvatine, and A. L. Lock. 2011. Nutrigenomics, rumen-derived bioactive fatty acids, and the regulation of milk fat synthesis. Annu. Rev. Nutr. 31:299-319.

Baumgard, L. H., J. K. Sangster, and D. E. Bauman. 2001. Milk fat synthesis in dairy cows is progressively reduced by increasing supplemental amounts of trans-10, cis-12 conjugated linoleic acid (CLA). J. Nutr. 131:1764-1769.

Berg, L. C., P. D. Thomsen, P. H. Andersen, H. E. Jensen, and S. Jacobsen. 2011. Serum amyloid A is expressed in histologically normal tissues from horses and cattle. Vet. Immunol. Immunopathol. 144:155-159.

Bernal-Santos, G., J. W. Perfield II, D. M. Barbano, D. E. Bauman, and T. R. Overton. 2003. Production responses of dairy cows to dietary supplementation with conjugated linoleic acid (CLA) during the transition period and early lactation. J. Dairy Sci. 86:3218-3228.

Bustin, S. A., V. Benes, J. A. Garson, J. Hellemans, J. Huggett, M. Kubista, R. Mueller, T. Nolan, M. W. Pfaffl, G. L. Shipley, J. Vandesompele, and C. T. Wittwer. 2009. The MIQE guidelines: Minimum information for publication of quantitative real-time PCR experiments. Clin. Chem. 55:611-622.

Castañeda-Gutiérrez, E., T. R. Overton, W. R. Butler, and D. E. Bauman. 2005. Dietary supplements of two doses of calcium salts of conjugated linoleic acid during the transition period and early lactation. J. Dairy Sci. 88:1078-1089.

Ceciliani, F., J. J. Ceron, P. D. Eckersall, and H. Sauerwein. 2012. Acute phase proteins in ruminants. J. Proteomics 75:4207-4231.

Chiba, T., C. Y. Han, T. Vaisar, K. Shimokado, A. Kargi, M.-H. Chen, S. Wang, T. O. McDonald, K. D. O'Brien, J. W. Heinecke, and A. Chait. 2009. Serum amyloid A3 does not contribute to circulating SAA levels. J. Lipid Res. 50:1353-1362. 
de Beer, M. C., F. C. de Beer, C. J. Gerardot, D. R. Cecil, N. R. Webb, M. L. Goodson, and M. S. Kindy. 1996. Structure of the mouse Saa4 gene and its linkage to the serum amyloid A gene family. Genomics 34:139-142.

Dilda, F., L. F. Pisani, M. M. Rahman, S. Modina, I. Tessaro, P. Sartorelli, F. Ceciliani, and C. Lecchi. 2012. Distribution of acute phase proteins in the bovine forestomachs and abomasum. Vet. J. 192:101-105.

Ebeling, P., A. M. Teppo, H. A. Koistinen, J. Viikari, T. Rönnemaa, M. Nissén, S. Bergkulla, P. Salmela, J. Saltevo, and V. A. Koivisto. 1999. Troglitazone reduces hyperglycaemia and selectively acutephase serum proteins in patients with type II diabetes. Diabetologia 42:1433-1438.

Eckersall, P. D., and R. Bell. 2010. Acute phase proteins: Biomarkers of infection and inflammation in veterinary medicine. Vet. J. $185: 23-27$

Fasshauer, M., J. Klein, S. Kralisch, M. Klier, U. Lossner, M. Bluher, and R. Paschke. 2004. Serum amyloid A3 expression is stimulated by dexamethasone and interleukin-6 in 3T3-L1 adipocytes. J. Endocrinol. 183:561-567.

Faty, A., P. Ferré, and S. Commans. 2012. The acute phase protein serum amyloid A induces lipolysis and inflammation in human adipocytes through distinct pathways. PLoS ONE 7:e34031.

GfE (German Society of Nutrition Physiology). 2001. Ausschuss für Bedarfsnormen der Gesellschaft für Ernährungsphysiologie. Nr. 8. Empfehlungen zur Energie- und Nährstoffversorgung der Milchkühe und Aufzuchtrinder (Recommendations of energy and nutrient supply for dairy cows and breeding cattle). DLG-Verlag, Frankfurt am Main, Germany.

Graugnard, D. E., K. M. Moyes, E. Trevisi, M. J. Khan, D. Keisler, J. K. Drackley, G. Bertoni, and J. J. Loor. 2013. Liver lipid content and inflammometabolic indices in peripartal dairy cows are altered in response to prepartal energy intake and postpartal intramammary inflammatory challenge. J. Dairy Sci. 96:918-935.

Han, C. Y., S. Subramanian, C. K. Chan, M. Omer, T. Chiba, T. N. Wight, and A. Chait. 2007. Adipocyte-derived serum amyloid A3 and hyaluronan play a role in monocyte recruitment and adhesion. Diabetes 56:2260-2273.

Hosseini, A., C. Behrendt, P. Regenhard, H. Sauerwein, and M. Mielenz. 2012. Differential effects of propionate or $\beta$-hydroxybutyrate on genes related to energy balance and insulin sensitivity in bovine white adipose tissue explants from a subcutaneous and a visceral depot. J. Anim. Physiol. Anim. Nutr. (Berl.) 96:570-580.

Humblet, M.-F., H. Guyot, B. Boudry, F. Mbayahi, C. Hanzen, F. Rollin, and J.-M. Godeau. 2006. Relationship between haptoglobin, serum amyloid A, and clinical status in a survey of dairy herds during a 6-month period. Vet. Clin. Pathol. 35:188-193.

Husebekk, A., G. Husby, K. Sletten, B. Skogen, and K. Nordstoga. 1988. Characterization of bovine amyloid proteins SAA and AA. Scand. J. Immunol. 27:739-743.

Hutchinson, I. A., A. A. Hennessy, R. J. Dewhurst, A. C. Evans, P. Lonergan, and S. T. Butler. 2012. The effect of strategic supplementation with trans-10, cis-12 conjugated linoleic acid on the milk production, estrous cycle characteristics, and reproductive performance of lactating dairy cattle. J. Dairy Sci. 95:2442-2451.

Larson, M. A., A. Weber, A. T. Weber, and T. L. McDonald. 2005. Differential expression and secretion of bovine serum amyloid A3 (SAA3) by mammary epithelial cells stimulated with prolactin or lipopolysaccharide. Vet. Immunol. Immunopathol. 107:255-264.

Lecchi, C., F. Dilda, P. Sartorelli, and F. Ceciliani. 2012. Widespread expression of SAA and Hp RNA in bovine tissues after evaluation of suitable reference genes. Vet. Immunol. Immunopathol. 145:556-562.

Lin, Y., M. W. Rajala, J. P. Berger, D. E. Moller, N. Barzilai, and P. E. Scherer. 2001. Hyperglycemia-induced production of acute phase reactants in adipose tissue. J. Biol. Chem. 276:42077-42083.

Martinez, K., A. Kennedy, T. West, D. Milatovic, M. Aschner, and M. McIntosh. 2010. Trans-10, cis-12-conjugated linoleic acid instigates inflammation in human adipocytes compared with preadipocytes. J. Biol. Chem. 285:17701-17712.
McDonald, T. L., M. A. Larson, D. R. Mack, and A. Weber. 2001. Elevated extrahepatic expression and secretion of mammary-associated serum amyloid A 3 (M-SAA3) into colostrum. Vet. Immunol. Immunopathol. 83:203-211.

Molenaar, A. J., D. P. Harris, G. H. Rajan, M. L. Pearson, M. R. Callaghan, L. Sommer, V. C. Farr, K. E. Oden, M. C. Miles, R. S. Petrova, L. L. Good, K. Singh, R. D. McLaren, C. G. Prosser, K. S. Kim, R. J. Wieliczko, M. H. Dines, K. M. Johannessen, M. R. Grigor, S. R. Davis, and K. Stelwagen. 2009. The acute-phase protein serum amyloid A3 is expressed in the bovine mammary gland and plays a role in host defence. Biomarkers 14:26-37.

Moore, C. E., H. C. Hafliger, O. B. Mendivil, S. R. Sanders, D. E. Bauman, and L. H. Baumgard. 2004. Increasing amounts of conjugated linoleic acid progressively reduces milk fat synthesis immediately postpartum. J. Dairy Sci. 87:1886-1895.

Mukesh, M., M. Bionaz, D. E. Graugnard, J. K. Drackley, and J. J. Loor. 2010. Adipose tissue depots of Holstein cows are immune responsive: Inflammatory gene expression in vitro. Domest. Anim. Endocrinol. 38:168-178.

Murata, H. 2007. Stress and acute phase protein response: An inconspicuous but essential linkage. Vet. J. 173:473-474.

Pappritz, J., U. Meyer, R. Kramer, E.-M. Weber, G. Jahreis, J. Rehage, G. Flachowsky, and S. Dänicke. 2011. Effects of long-term supplementation of dairy cow diets with rumen-protected conjugated linoleic acids (CLA) on performance, metabolic parameters and fatty acid profile in milk fat. Arch. Anim. Nutr. 65:89-107.

Perfield, J. W., II, A. L. Lock, J. M. Griinari, A. Saebø, P. Delmonte, D. A. Dwyer, and D. E. Bauman. 2007. Trans-9, cis-11 conjugated linoleic acid reduces milk fat synthesis in lactating dairy cows. J. Dairy Sci. 90:2211-2218.

Poitou, C., N. Viguerie, R. Cancello, R. De Matteis, S. Cinti, V. Stich, C. Coussieu, E. Gauthier, M. Courtine, J. D. Zucker, G. S. Barsh, W. Saris, P. Bruneval, A. Basdevant, D. Langin, and K. Clément. 2005. Serum amyloid A: Production by human white adipocyte and regulation by obesity and nutrition. Diabetologia 48:519-528.

Reigstad, C. S., G. Ö. Lundén, J. Felin, and F. Bäckhed. 2009. Regulation of serum amyloid A3 (SAA3) in mouse colonic epithelium and adipose tissue by the intestinal microbiota. PLoS ONE 4:e5842.

Reynolds, C. M., and H. M. Roche. 2010. Conjugated linoleic acid and inflammatory cell signalling. Prostaglandins Leukot. Essent. Fatty Acids 82:199-204.

Rubin, D., J. Herrmann, D. Much, M. Pfeuffer, C. Laue, P. Winkler, U. Helwig, D. Bell, A. Auinger, S. Darabaneanu, A. Ruether, and J. Schrezenmeir. 2012. Influence of different CLA isomers on insulin resistance and adipocytokines in pre-diabetic, middle-aged men with PPAR $\gamma 2$ Pro12Ala polymorphism. Genes Nutr. 7:499-509.

Saremi, B., A. Al-Dawood, S. Winand, U. Müller, J. Pappritz, D. von Soosten, J. Rehage, S. Dänicke, S. Häussler, M. Mielenz, and H. Sauerwein. 2012a. Bovine haptoglobin as an adipokine: Serum concentrations and tissue expression in dairy cows receiving a conjugated linoleic acids supplement throughout lactation. Vet. Immunol. Immunopathol. 146:201-211.

Saremi, B., H. Sauerwein, S. Dänicke, and M. Mielenz. 2012b. Technical note: Identification of reference genes for gene expression studies in different bovine tissues focusing on different fat depots. J. Dairy Sci. 95:3131-3138.

Scheja, L., B. Heese, H. Zitzer, M. D. Michael, A. M. Siesky, H. Pospisil, U. Beisiegel, and K. Seedorf. 2008. Acute-phase serum amyloid A as a marker of insulin resistance in mice. Exp. Diabetes Res. 2008:230837.

Sommer, G., S. Weise, S. Kralisch, P. E. Scherer, U. Lössner, M. Blüher, M. Stumvoll, and M. Fasshauer. 2008. The adipokine SAA3 is induced by interleukin-1beta in mouse adipocytes. J. Cell. Biochem. 104:2241-2247.

Uhlar, C. M., and A. S. Whitehead. 1999. Serum amyloid A, the major vertebrate acute-phase reactant. Eur. J. Biochem. 265:501-523.

Vandesompele, J., K. De Preter, F. Pattyn, B. Poppe, N. Van Roy, A. De Paepe, and F. Speleman. 2002. Accurate normalization of real-time quantitative RT-PCR data by geometric averaging of multiple internal control genes. Genome Biol. 3:research0034. 
von Soosten, D., U. Meyer, E. M. Weber, J. Rehage, G. Flachowsky, and S. Dänicke. 2011. Effect of trans-10, cis-12 conjugated linoleic acid on performance, adipose depot weights, and liver weight in early-lactation dairy cows. J. Dairy Sci. 94:2859-2870.

Wang, L., and W. Colón. 2007. Effect of zinc, copper, and calcium on the structure and stability of serum amyloid A. Biochemistry 46:5562-5569.

Weber, A., A. T. Weber, T. L. McDonald, and M. A. Larson. 2006. Staphylococcus aureus lipotechoic acid induces differential expres- sion of bovine serum amyloid A3 (SAA3) by mammary epithelial cells: Implications for early diagnosis of mastitis. Vet. Immunol. Immunopathol. 109:79-83.

Yang, R.-Z., M.-J. Lee, H. Hu, T. I. Pollin, A. S. Ryan, B. J. Nicklas, S. Snitker, R. B. Horenstein, K. Hull, N. H. Goldberg, A. P. Goldberg, A. R. Shuldiner, S. K. Fried, and D.-W. Gong. 2006. Acute-phase serum amyloid A: An inflammatory adipokine and potential link between obesity and its metabolic complications. PLoS Med. 3:e287. 